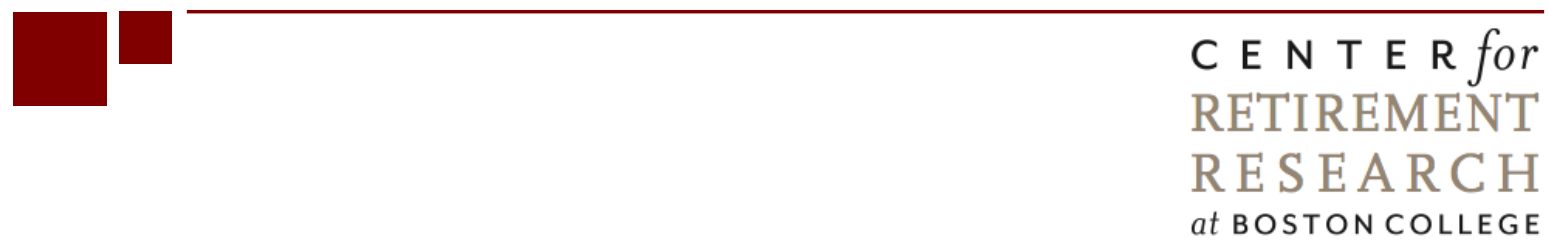

\title{
THE TRADEOFF BETWEEN HEALTH AND WEALTH IN RETIREMENT DECISIONS
}

\author{
Kristine M. Brown \\ CRR WP 2014-7 \\ Submitted: January 2014 \\ Released: May 2014
Center for Retirement Research at Boston College
Hovey House
140 Commonwealth Ave
Chestnut Hill, MA 02467 \\ Tel: 617-552-1762 Fax: 617-552-0191 \\ http://crr.bc.edu
}

Kristine M. Brown is an assistant professor at the School of Labor \& Employment Relations and the Department of Economics at the University of Illinois at Urbana-Champaign. The research reported herein was pursuant to a grant from the U.S. Social Security Administration (SSA), funded as part of the Retirement Research Consortium (RRC). The findings and conclusions expressed are solely those of the author and do not represent the views of SSA, any agency of the federal government, the RRC, the University of Illinois at Urbana-Champaign, or Boston College.

(C) 2014, Kristine M. Brown. All rights reserved. Short sections of text, not to exceed two paragraphs, may be quoted without explicit permission provided that full credit, including (C) notice, is given to the source. 


\begin{abstract}
About the Center for Retirement Research
The Center for Retirement Research at Boston College, part of a consortium that includes parallel centers at the University of Michigan and the National Bureau of Economic Research, was established in 1998 through a grant from the Social Security Administration. The Center's mission is to produce first-class research and forge a strong link between the academic community and decision-makers in the public and private sectors around an issue of critical importance to the nation's future. To achieve this mission, the Center sponsors a wide variety of research projects, transmits new findings to a broad audience, trains new scholars, and broadens access to valuable data sources.
\end{abstract}

\author{
Center for Retirement Research at Boston College \\ Hovey House \\ 140 Commonwealth Avenue \\ Chestnut Hill, MA 02467 \\ phone: 617-552-1762 fax: 617-552-0191 \\ e-mail: crr@bc.edu \\ crr.bc.edu
}

Affiliated Institutions:

The Brookings Institution

Massachusetts Institute of Technology

Syracuse University

Urban Institute 


\begin{abstract}
In the United States, because access to health insurance is tied to employment, the availability of retiree health insurance interacts with post-retirement income to shape the retirement decision. This paper uses administrative data from the California Department of Education to estimate the rate at which individuals' trade off post-retirement health insurance benefits for a longer retirement and for retirement income benefits. The sensitivity of retirement to the return to working in terms of post-retirement health insurance is estimated. This estimate is then compared to the sensitivity of retirement to pension generosity in order to determine the implied rate at which individuals substitute between health insurance and pension benefits. The two estimation methods used leverage plausibly exogenous benefit variation driven by the sharp features of the retiree benefit programs. The results imply that individuals will delay retirement to become eligible for retiree health benefits, but that the effect is small relative to the effect of pension benefits on retirement timing.
\end{abstract}




\section{Introduction}

Public programs that provide income and health insurance to retirees, including Social Security and Medicare, are experiencing projected shortfalls, while many public employee retirement programs are severely underfunded. In response, reforms of these programs that aim to reduce taxpayer liabilities by reducing benefits have been proposed. Yet it is not clear how alternative options for reform will affect recipient wellbeing. In the U.S., retirement, and early retirement in particular, exposes individuals to both a reduction of income and the loss of health insurance coverage. In this context, retirement income benefits and the availability of post-retirement health insurance will jointly shape retirement decisions. However, the relative valuation of pension and retiree health benefits is not well-understood. Knowledge about individuals' willingness to trade off retirement income and health insurance is essential to creating efficient policy and to predicting how changes in social insurance programs and employer-sponsored retirement benefits will affect elderly labor supply and well-being.

In this paper, I estimate the direct effect of retiree health insurance benefit accrual on the retirement timing of California public school teachers and calculate the implied substitution rate between a dollar of pension benefits and a dollar of retiree health benefits. I use a detailed administrative data set covering the five largest school districts in the state for academic years 2003-07 to obtain an unbiased estimate of the elasticity of retirement timing with respect to the return to working in terms of health benefits. The empirical strategy exploits the plausibly exogenous variation in eligibility for retiree health benefits that is created by program nonlinearities within and across school districts. The health benefit elasticity estimates are compared to the analogous estimates of the effect of pension accrual on retirement timing to generate an implied substitution rate. The results of two complementary empirical approaches imply that individuals are willing to delay retirement in order to gain retiree health benefits, but that the magnitude of this effect is smaller than the effect of pension accrual.

There is a large literature that finds individuals are more likely to retire early if they have access to retiree or public health insurance. (See Monk and Munnell (2009) and Gruber and Madrian (2004) for a review of the literature.) However, estimation techniques that assume that retirees with diverse health insurance and pension benefits are otherwise identical after controlling for observable characteristics, are unsatisfactory as the potential for endogenous sorting and other forms of potential omitted variable bias make it difficult to infer the true causal effect of health benefits on retirement. This paper expands the relatively small literature that uses plausibly exogenous variation in health insurance coverage and sharp incentives created by program features to overcome potential omitted variable bias. Gruber and Madrian (1995) and Boyle and Lahey 
(2010) which examine the expansion of COBRA and VA health benefits respectively and find that access to health insurance increases the probability retirement for most individuals are examples. Further, the majority of studies examine how the level of retiree health insurance affects the decision of when to retire, while this project focuses on estimating individuals willingness to trade post-retirement health insurance benefits for a longer retirement or for larger retirement income benefits.

The California public school system is an advantageous setting in which to examine the tradeoff of health benefits with leisure and pension benefits and to address the inherent estimation challenges. Like many other states, California is struggling to cover retiree income and health benefits. The teachers' pension is underfunded at 69 percent funded (CalSTRS, 2012) and the school-district-run retiree health insurance programs also have large unfunded liabilities. ${ }^{1}$. First, it offers a large and relatively homogeneous population of workers with the same occupation that face rigid district-level wage and benefit schedules. Relative to large survey data sets, this leaves less room for unobserved individual differences in taste to be driving variation in observed retirement incentives. Second, the retirement pension is regulated at the state level, while other benefits are negotiated at the district level, decoupling the incentives of the two programs. Finally, retiree health insurance eligibility is typically determined by a strict service requirement. This feature introduces a sharp, plausibly exogenous distortion to the return to work, which varies across school districts and can be exploited in the empirical strategy.

I use two empirical strategies to estimate the response of retirement timing to retiree health insurance accrual. The first examines the distribution of retirements around the eligibility threshold. At the eligibility threshold, the individual gains the present value of the stream of future retiree health benefits. This jump, which can be illustrated as a discontinuity in the lifetime budget constraint, creates a large incentive to delay retirement for those that are just under the eligibility threshold. The response to this incentive can be observed as a dip in the density of the distribution of retirements just before the threshold. The more responsive individuals are, the larger the dip will be. The magnitude of this gap and the dollar value of attaining retiree health insurance eligibility are estimated and used to calculate the elasticity of labor supply with respect to the accrual of retiree health insurance benefits. This estimate is compared to a similar estimate of labor supply elasticity with respect to pension wealth accrual from the literature, and is found to be substantially smaller.

The second empirical strategy uses a regression framework to simultaneously estimate the effect of

\footnotetext{
${ }^{1}$ The unfunded actuarial accrued liability of the pension is $\$ 63,840$ million as of June 2011 (CalSTRS, 2012). Further, for the 502 (out of 857) districts and county education offices reporting a completed actuarial study of retiree health benefits between 2003 and 2012, the average liability is over $\$ 37$ million for a total of nearly $\$ 19$ billion statewide (California Department of Education, 2012).
} 
retiree health insurance benefit accrual and pension wealth accrual on the probability of retirement. Controls for age, years of service, and compensation while employed are used to narrow the identifying variation to that created by the sharp program rules. The source of identification in this strategy is less salient than in the discontinuity estimation, but this strategy has the advantage of providing estimates of the effect retiree health benefits and pension benefits on retirement within the same framework. The results corroborate the discontinuity estimates - the probability of retirement is decreasing in the accrual of retiree health insurance benefits, but the estimated coefficient is substantially smaller than that on pension wealth accrual.

The remainder of this paper is organized as follows. In Section 2, I provide an overview of the retirement benefits of California teachers and describe the administrative data. Section 3 provides a brief description of the underlying model and empirical strategy. The two estimation strategies and the results of each are outlined in the section. Section 4 concludes.

\section{Background and data}

The retirement benefits of California public school teachers are determined through collective bargaining at the school district level and by state policy. Teachers are covered by a state teachers' pension (CalSTRS), which provides a defined benefit retirement plan. ${ }^{2}$ State law determines the pension contribution rates, retirement ages and associated benefit amounts. The pension parameters can only be changed by legislative action and such changes apply to all school districts in the state. Teachers contribute 8 percent of their salaries while working, and on average the retirement benefits for retirees are 59 percent of their final salaries. Teachers retiring in years 2003-07 can begin collecting a reduced pension benefit as early as age 55 (or age 50 with 30 years of service), though the program normal retirement age is 60 and the value of the pension can be further increased by working a few years beyond age 60 .

Retiree health insurance (RHI) benefits, on the other hand, are determined at the school district level and are written into the collective bargaining agreements between the teachers' unions and the districts. Although school districts are required to allow retired teachers to continue their health insurance coverage, the district is not required to include retirees in the same insurance pool as current employees or to provide premium support. As a result there is considerable variation across districts in the value of RHI benefits. It has been most common for employers to partially cover premiums until Medicare eligibility at age 65, but 19 percent offer no contributions for retirees (CalSTRS, 2006), and the generosity of RHI benefits have been decreasing in recent years. Further, premium support is commonly tied to a threshold district service

\footnotetext{
${ }^{2}$ They are not simultaneously covered by Social Security, but do contribute to Medicare.
} 


\begin{tabular}{lcccc}
\hline \hline \multicolumn{2}{l}{ Teachers ages 55-79, academic years $2003-07$} & & \\
& Mean & Std. Dev. & Mean & Std. Dev. \\
\hline Age & 58.475 & 3.815 & 58.099 & 3.577 \\
District service & 19.815 & 10.268 & 13.718 & 5.650 \\
Years of teaching & 22.353 & 10.738 & 17.808 & 8.446 \\
Fraction with MA or higher & 0.517 & 0.500 & 0.454 & 0.498 \\
Fraction female & 0.716 & 0.451 & 0.742 & 0.438 \\
Fraction white & 0.680 & 0.466 & 0.765 & 0.424 \\
Salary (\$100k) & 0.782 & 0.109 & 0.753 & 0.105 \\
Pension wealth (\$100k) & 6.518 & 4.167 & 4.075 & 2.050 \\
Pension wealth accrual $(\$ 100 k)$ & 0.348 & 0.417 & 0.319 & 0.175 \\
\hline
\end{tabular}

Table 1: Staffing summary statistics

Notes: All financial variables are reported in 2013 dollars.

requirement.

This paper uses administrative data collected by the California Department of Education to exploit the program rules of the pension and RHI benefit programs to estimate the relative importance of each type of deferred compensation in the the retirement decision. I match information from the annual staffing census and annual salary and benefits survey at the school district level. Given data availability (described below), the analysis in this paper focuses on the five largest public school districts in California, which are, in descending order, Los Angeles Unified, San Diego Unified, Long Beach Unified, Fresno Unified, and Elk Grove Unified, and on the academic years 2003-2007.

Staffing data.- The California Department of Education conducts an annual staffing survey in October of each academic year. Employment and demographic information is collected from all teachers employed by a California public school district. This information includes the employing school and district, years of teaching experience, age, and education.

Table 1 shows the average characteristics of all retirement-eligible teachers employed by the five largest districts in the state and of the subset of these teachers that will be used in the analysis. ${ }^{3}$ The average age of retirement eligible teachers in these districts for academic years 2003-07 is 58.5 and on average they have been teaching in their current school district for almost 20 years. As expected, the large majority of teachers are women and 68 percent identify their race as white. These experienced teachers earn on average

\footnotetext{
${ }^{3}$ The analysis will focus on teachers close to the RHI eligibility thresholds. The sample restrictions are described in more detail in section 3 .
} 
over $\$ 78,000$ (in 2013 dollars) and expect to receive over 0.65 million dollars in retirement income from the state teachers' pension system. Relative to the total population of retirement-eligible teachers, the teachers considered in the analysis have been teaching in the district six fewer years, are less likely to hold a masters degree, are paid a lower salaries, and have accrued smaller pensions.

The key outcome variable for the analysis is retirement. The staffing survey data provides a snapshot of the teachers working in a particular school at a point in time, but does not report retirement events or include a unique teacher identifier that can be used to track individual teachers across years to infer their exits. Therefore, I construct a school district level cohort retirement measure. Specifically, in each year $t$ cohorts of retirement-eligible teachers are defined by the school district, age in an arbitrary fixed year $T$, and years of district service in year $T$. The number of retirements for each cohort is then calculated as the difference between the number of teachers in cohort $c$ in year $t+1$ and the number of teachers in cohort $c$ in year $t$. For example, suppose there are 10 teachers in Los Angeles Unified that are age 56 and have been teaching in the district for 10 years in year $t$ and in year $t+1$ there are 8 teachers in the district that are age 57 with 11 years of service. The change in the number of teachers in this cohort is 2 , so this would be counted as 2 retirements in year $t$. It should be noted that a retirement-eligible teacher may exit a district for reasons other than retirement, but such exits will be counted as retirements in this measure. Also, teachers that are eligible to retire (as determined by age) may begin teaching in a particular district in year $t+1$ and these individuals are not differentiated from incumbent teachers with the same characteristics in this measure. However despite the inability to track individuals, the empirical average rate of retirement using this measure is 9 percent in Los Angeles Unified, which is in line with the retirement rate calculated by Brown and Laschever (2012) using a different data set of LA Unified teachers that indicated actual retirement events.

Salary and benefits data.- The salary schedules and health benefits for each school district are available from an annual compensation survey conducted by the California Department of Education. The collectively bargained salary schedules indicate the salary associated with each level of service and education level. Because the schedules are so rigid, it is possible to assign salaries to teachers in the staffing data accurately. The average salary for each level of teaching experience in each district in each academic year is calculated and this data is matched to the staffing data by teaching experience, district, and academic year.

The state teachers' pension benefit formula is a function of salary, age and years of service, so these data are sufficient to calculate each teacher's pension wealth - the present value of the expected stream of retirement income if she retires in the current period - and the accrual of pension wealth associated with an additional year of work. See appendix A for details. All else equal, it is expected that an individual with greater pension wealth will be more likely to retire, while an individual with a higher rate of pension accrual 
(and/or higher salary) will be less likely to retire. The average values of pension wealth and accrual are provided in Table 1.

The benefits portion of the data set contains all health insurance options for active employees, retirees under age 65, and Medicare-eligible retirees for each school district and year. This includes the name of the plan, the annual cost of the plan, and the dollar amount the district contributes to cover the premium. The options for Medicare-eligible retirees are typically the less costly Medigap plans. Importantly the district contributions reflected in this data set are only given to those that are eligible for RHI benefits. Eligibility requirements are set at the district level and are unfortunately not available in this data set. Information culled from the school district HR materials and collective bargaining agreements is used to determine the district service threshold for RHI eligibility in the largest 5 school districts in California for retirements in years 2003-07. An overview of the RHI benefits by district is provided in Table 2.

In order to compare how RHI benefits are valued relative to pension benefits, via their effect on retirement decisions, it is necessary to generate measures of the incentive effects of RHI benefits that are analogous to the pension incentive measures described above. To capture the generosity of retiree health benefits in dollar terms, I focus on the maximum dollar amount the district contributes to health insurance premiums for individual plans (i.e. not family plans). RHI wealth can then be calculated as the present value of the expected stream RHI premium contributions from the district for retirement in the current period. RHI wealth will increase discontinuously from zero to its maximum value at the eligibility threshold. For this reason, a single year accrual measure will not capture the incentive to delay retirement for those below the eligibility threshold. One way to capture this is with an average accrual rate - the value of RHI benefits when eligibility is reached divided by the number of years from the threshold. ${ }^{4}$ The average values of RHI wealth and RHI average accrual for the sample under study are $\$ 68,000$ and $\$ 21,700$.

\section{Empirical strategy and results}

The goal of the empirical analysis is to estimate the implied rate at which individuals substitute between retiree health insurance and retirement income by comparing how individuals delay retirement in response to the return to working in terms of each type of benefit. The canonical lifetime labor supply model implies that if individuals value health insurance (or pension) benefits, an increase in the amount of benefits associated with an additional year of work will cause an individual to delay retirement. Additionally, an increase in the level of lifetime benefits at the current level of service will generate an income effect and incentivize

\footnotetext{
${ }^{4}$ The precise calculation of this measure varies slightly across estimation strategies and will be discussed further in Section 3 .
} 


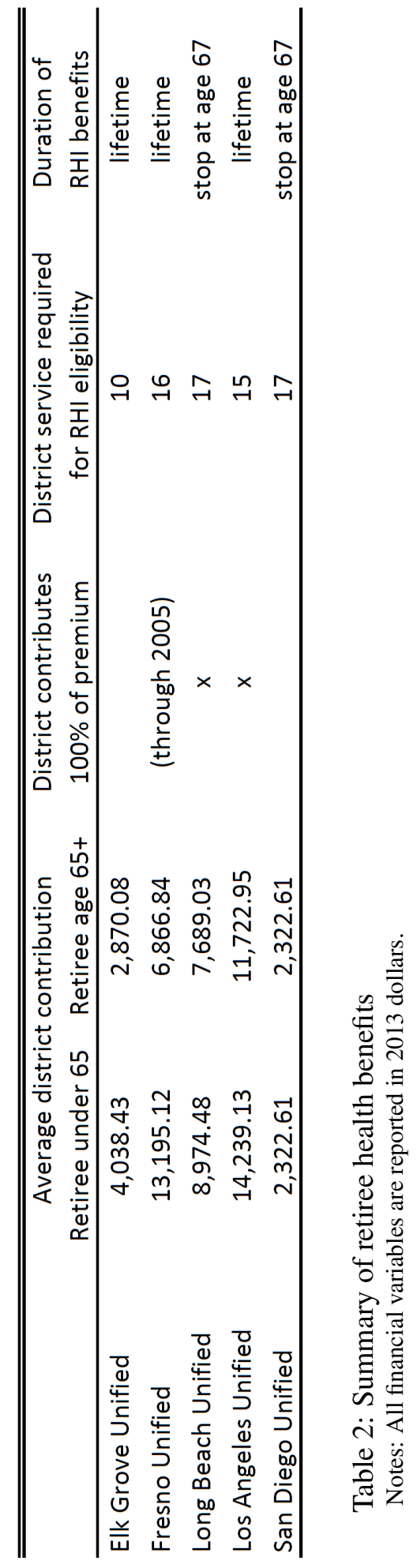


individuals to retire earlier.

Two complementary estimation methods are used to estimate the effect of RHI accrual on labor supply. The first uses the sharp discontinuity in the level of RHI benefits at the eligibility service threshold to estimate the elasticity of labor supply with respect to the health insurance return to working. The second strategy uses OLS to estimate the effect of RHI accrual and RHI wealth on the probability of retirement in a given year. In both cases the health insurance effects are compared to the corresponding effect of pension financial incentives on retirement. In the second strategy, the pension estimates are produced within the same OLS estimation procedure as the RHI estimates.

\subsection{The elasticity of labor supply}

The retiree health insurance eligibility thresholds create a plausibly exogenous, large, discontinuous jump in the level of RHI benefits. As noted by Gustman and Steinmeier (1994), by working the additional year to eligibility the worker gains the present value of the future stream of retiree health benefits. A stylized budget constraint depicting this discontinuity is shown in Figure 1. It is unlikely that the exact service location of the RHI eligibility threshold coincides with sharp changes in other unobserved factors that would affect the retirement decision and confound the results. Sharp changes in pension accrual are associated with particular ages rather than service levels and variation in the RHI threshold across districts makes it unlikely that these key ages and service levels are aligned for a significant fraction of the population. Further, school districts have changed these thresholds (upward) over time to counter increasing health care costs. It seems unlikely that this reflects a similar sharp change in the taste for leisure and pension features remained unchanged during the same period. This implies that the distortion to the return to work created by the RHI eligibility thresholds can be leveraged to produce an unbiased estimate of the elasticity of labor supply with respect to the accrual of RHI benefits.

Estimating the elasticity of labor supply (years of service) with respect to health insurance benefits, requires estimating the change in retirement timing created by the RHI eligibility threshold relative to the additional financial incentive that it creates. Assume that when individuals face a linear budget constraint (an extension of the left segment of the budget constraint in Figure 1), retirements will be smoothly distributed across years of service according to density $h(S)$. With the introduction of the discontinuity, individuals that would retire just before the RHI eligibility threshold along the linear budget constraint will have an incentive to substitute away from leisure to health benefits by delaying retirement to the threshold. In this context, there exists an individual that will be exactly indifferent between her retirement date in the absence of RHI, at $S_{0}$, and the RHI eligibility threshold $S_{R H I}$, as shown in Figure 1. Absent frictions, all individuals retiring 


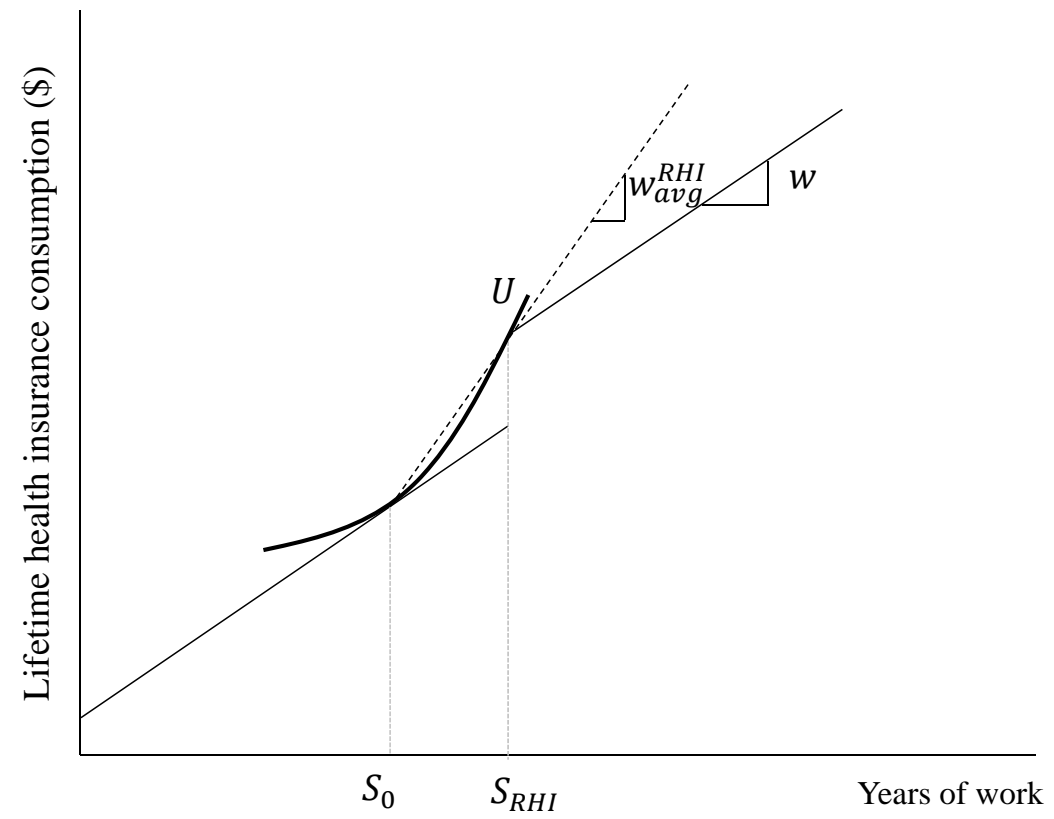

Figure 1: Health insurance budget constraint 


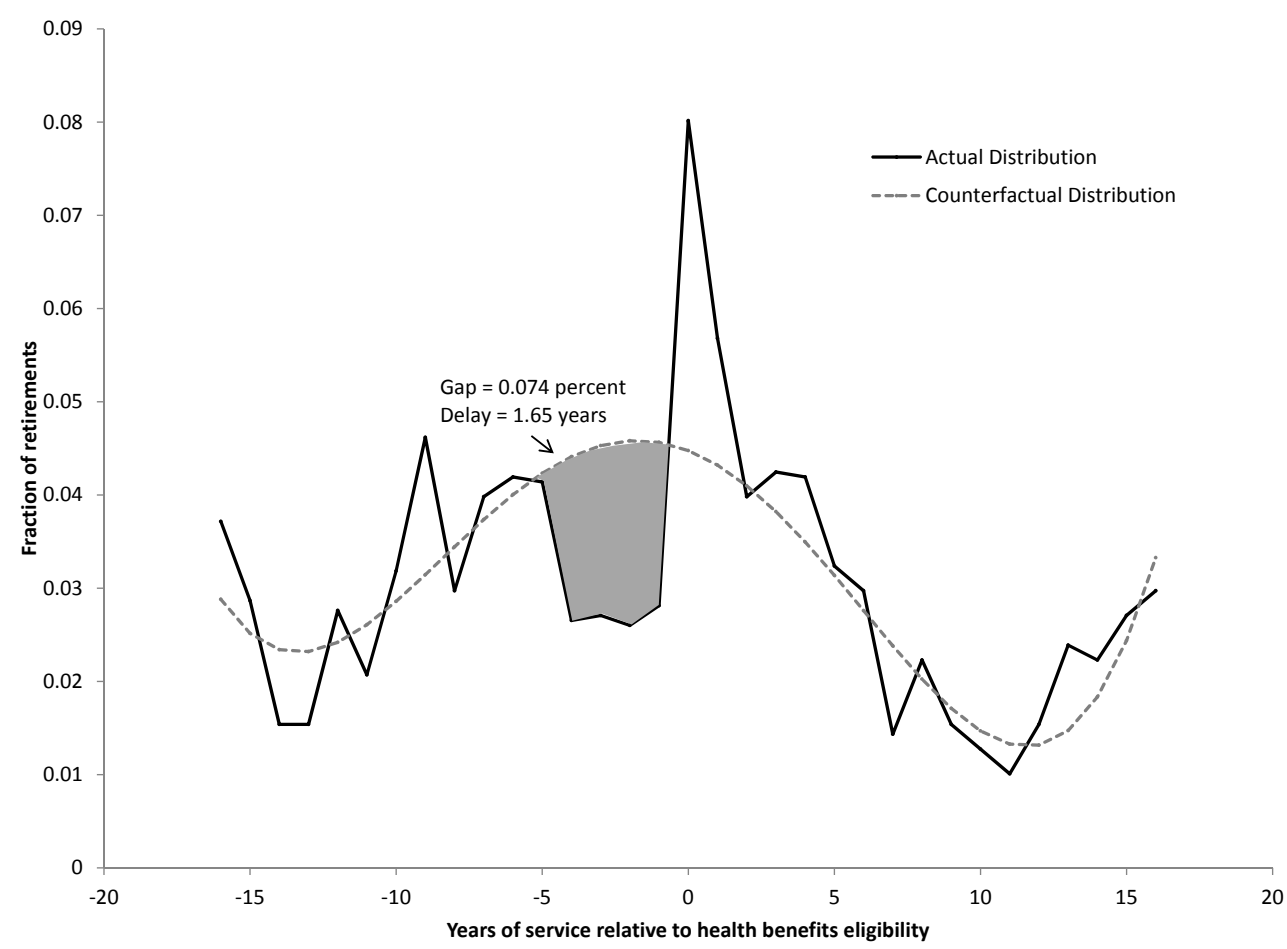

Figure 2: Distribution of retirements relative to RHI eligibility

between $S_{0}$ and $S_{R H I}$ along the linear budget constraint will also delay to the threshold. This response would create a dip in the previously smooth retirement distribution before the eligibility threshold and a spike at the eligibility threshold.

The distribution of retirements relative to the RHI eligibility service threshold is shown in Figure 2. A measure of years from RHI eligibility is generated so that data from the five school districts can be pooled. Using the pooled data, the retirement distribution for each year 2003-07 is calculated, and the average of these annual profiles is shown in the figure. The first year of eligibility is year 0 . The distribution indicates a clear dip in retirements prior to RHI eligibility with a spike in the eligibility year.

Following methods developed in Saez (2010) and Kleven and Waseem (2012) the distortions in the retirement distribution corresponding to the distortion in the budget constraint can be used to estimate the labor supply elasticity. The takeaway from these empirical models is that the total mass missing from the retirement distribution just before the RHI eligibility threshold is proportional to the labor supply elasticity. 
Further, dividing this missing mass by the counterfactual mass in the presence of a linear budget constraint yields an estimate for the number of years that individuals delay retirement in response to the RHI eligibility incentive effects.

More formally, as discussed in Brown (2013), the individual at $S_{0}$ will move to $S_{R H I}$ and the change in lifetime labor supply in response to the discontinuity is $d S=S_{R H I}-S_{0}$. Each individual with $S_{0} \leq S^{*} \leq S_{R H I}$ when the budget constraint is linear will also delay retirement to the the discontinuity, while those with $S^{*}<S_{0}$ will not adjust their retirement dates at all. With a homogeneous elasticity across the population and no frictions, this creates a gap in the retirement distribution such that there will be zero retirements between $S_{0}$ and $S_{R H I}$. The "missing" retirements will reappear exactly at $S_{R H I}$ creating a spike in the distribution at this point. These shifted retirements, $N^{G}=\int_{S_{0}}^{S_{R H I}} h(S) d S$ are proportional to the lifetime labor supply elasticity of substitution. Empirically the density does not go to zero preceding the gap, but in absence of optimization frictions the estimated elasticity can be interpreted as the average elasticity of the population.

The gap in the retirement distribution can be estimated by first be estimating the counterfactual distribution of retirements along a linear health benefit budget constraint, as it is not observed. Visual inspection of Figure 2 indicates that the dip in the retirement distribution occurs at 5 years before RHI eligibility and the corresponding spike occurs at $0-1$ years of eligibility. I therefore estimate the counterfactual by fitting a second order polynomial through the data excluding these years. This counterfactual density is shown by the dashed gray line in Figure 2. Next, the gap is estimated as the difference between this counterfactual distribution and the actual distribution. This is indicated by the shaded gray area in Figure 2. Scaling the gap by the counterfactual density implies that individuals are willing to delay retirement by $d S=1.65$ years in response to the health insurance gain for continued work.

The discontinuity does not create exogenous variation in the marginal return to work, but the marginal return in the presence of the discontinuity can be approximated as the average return to working over the range of service years that individuals are delaying retirement, so $w_{a v g}^{R H I}$ in Figure 1 is the average return to work between the estimated $S_{0}$ and $S_{R H I}$ when the discontinuity at $S_{R H I}$ is present. This effectively imposes a nonconvex kink at $S_{0}$ years of service as shown by the dashed line in Figure 1. Of course, faced with such a budget constraint, the individual that located at $S_{0}$ on the linear budget constraint would be better off retiring before $S_{R H I}$, so the estimated elasticity will be an upper bound for the true parameter.

The data from the five school districts are pooled and the elasticity estimation is bootstrapped (500 replications). The implied elasticity is 0.01267 and is statistically different from zero at the 1 percent level. Ideally, a similar estimation method could be used with this data to estimate the elasticity of lifetime labor supply with respect to pension wealth accrual. However, the key nonlinearities in the pension program occur 
in age rather than service and the integer age measure available in the current data is not precise enough to implement this procedure successfully. Brown (2013) uses another California teacher administrative data source to conduct such an analysis and finds that the implied elasticity with respect to pension accrual is 0.093 when estimated about a budget constraint discontinuity and that the relevant estimates using a similar method about a budget constraint kink are somewhat smaller, ranging from 0.031 to $0.075 .^{5}$ This implies that the accrual of one dollar of pension benefits has a 2.5-7.75 times larger effect on retirement behavior than the accrual of one dollar of retiree health benefits. Estimating the counterfactual density as the mean of the distribution to either side of the eligibility threshold, rather than fitting the polynomial, implies an even smaller elasticity with respect to RHI.

\subsection{The probability of retirement}

This section further explores the effect of retiree health benefits on retirement timing and their valuation relative to pension benefits in the retirement decision using an alternative specification and estimation strategy. The probability that individual $i$ in school district $d$ retires in year $t$ can be expressed as a function of current compensation and retirement benefits by

$$
R_{i, d, t}=\alpha+\beta_{1} R H I W_{i, d, t}+\beta_{2} R H I A c_{i, d, t}+\beta_{3} P W_{i, d, t}+\beta_{4} P A c_{i, d, t}+\theta X_{i, d, t}+\gamma_{t}+\delta_{d}+\varepsilon_{i, d, t},
$$

where RHIW and $P W$ are RHI wealth and pension wealth, RHIAc and PAc are RHI accrual and pension wealth accrual, $X$ are observable time-changing individual and district characteristics, and $\gamma_{t}$ and $\delta_{d}$ are year and district fixed effects. Individual teacher retirement events cannot be identified, so individual characteristics such education or race cannot be included in the estimation.

In order to reduce concerns about omitted variable bias, I fully control for age, years of service, and salary, which are the only factors entering the pension formula. Also years of service determines RHI eligibility in all districts, leaving the small differences in RHI eligibility thresholds across districts as the main source of identifying variation. In the case that the eligibility thresholds are not correlated with individual preferences and district characteristics that may affect retirement, the estimates of the effect RHI benefits on the probability of retirement will be unbiased.

In addition to examining only retirement eligible teachers in the five largest school districts in California, the sample is further restricted. It includes only teachers that will or have become RHI eligible between the

\footnotetext{
${ }^{5}$ The kink estimates are those in Table 2 of Brown (2013) that are specific to teachers with less than 30 years of service at age 60 - "low service" and to teachers in Los Angeles Unified. The kink estimates are not subject to the same overestimation as the discontinuity estimates.
} 
ages of 55 and 65. This restriction is in place because it is not possible to observe a retirement response to RHI eligibility unless the teacher is retirement eligible which does not occur until age 55 and the large majority of teachers will have retired by age 65 . Second, the sample is restricted to those that are within 10 years of eligibility. The final sample has 11,363 observations. In all specifications, financial measures are in 2013 dollars and standard errors are clustered at the district level.

The main results are presented in Table 3. The specifications in columns (1) and (2) include only simple indicators of RHI eligibility and controls for age, service, and years from eligibility. The results indicate that individuals are are 4.7-6.5 percent more likely to retire in the year they become eligible for districtsponsored retiree health benefits. This would be observed if individuals are responding to the RHI accrual and delaying retirement until eligibility or if the effective increase in wealth at RHI eligibility increases retirement rates or a combination of both. Columns (3) and (4) try to separate these effects by replacing the RHI eligibility measures with RHI wealth and RHI accrual. Both coefficients are of the expected sign, however only the coefficient on RHI accrual is statistically different from zero. The estimate implies that at $\$ 100,000$ increase in RHI accrual causes the probability of retirement to decrease by 3.4 percentage points.

Columns (5)-(6) add measures of pension wealth and accrual as well as additional controls for salary and the districts' contributions to health insurance premiums for active employees. These additional coefficients all have the expected sign. The probability of retirement is increasing in pension wealth and decreasing in pension accrual, current salary and active employee health benefits. The coefficients on RHI wealth and accrual do not change much moving across the columns. RHI accrual has a persistent negative effect on the probability of retiring.

Comparing the coefficient on 1-year pension wealth accrual to that of RHI accrual it appears that a dollar spent on pension benefits has a greater than 10 times larger effect on the retirement decision than a dollar spent on RHI benefits. These coefficients are statistically different at the 10 percent level or better in all specifications (5)-(8). This is a large effect and is consistent with the results from the previous section. It is expected that retiree health insurance would be highly valued, at least until Medicare eligibility, and that any school district commitments to cover a specified fraction of premiums would provide the added benefit of some protection against rising insurance costs. However, there is greater uncertainty over the value of RHI benefits than over pension benefits. Employers have considerably more leeway to adjust RHI benefits after retirement than the state has to adjust accrued pension benefits and in recent years employers have been more carefully examining their retiree health care obligations. In addition to cutting premium support, districts may choose to offer cheaper, less comprehensive plans. Further, retired teachers are able to buy health insurance through their district even if they do not receive premium support, and it may be that the 
value of this access to group insurance swamps the premium support obtained at the eligibility threshold, especially when pension dollars can be used to purchase anything.

The specifications (5)-(8) in Table 3 were also estimated with a sample further limited to those that were within 5 years of RHI eligibility to better hone in on the discontinuity in retiree health benefits. These results are shown in columns (1) - (4) of Table 4. The results are smaller but similar, though the standard errors are somewhat larger due to the smaller sample size. Also, because the RHI accrual is discontinuous, the accrual measure used may underestimate the effect if those far from eligibility, but with a high average accrual do not delay retirement. To address this an alternative measure of RHI accrual is constructed. This measure takes the value of zero if the teacher is 3 or more years away from RHI eligibility and is otherwise the same as the original accrual measure. The results, shown in columns (5)-(8) of Table 4 do not change substantially.

\section{Conclusion}

In this paper, I use two methods to estimate the direct effect of retiree health insurance benefit accrual on the retirement timing of California public school teachers and the implied substitution rate between a dollar of pension benefits and a dollar of retiree health benefits. Exploiting the plausibly exogenous variation in eligibility for retiree health benefits that is created by program nonlinearities within and across school districts, I find that the accrual of retiree health insurance benefits does affect retirement timing, but it is small relative to the effect of pension accrual.

Understanding retirees' relative valuation of retirement income and health insurance coverage is essential to efficiently coordinate Social Security and Medicare benefits and to efficiently reduce the costs of retiree benefits for public employees. Future work should examine whether this effect is modified when group insurance is not otherwise available and when RHI benefits guarantee a fraction of cost coverage versus a dollar value. 


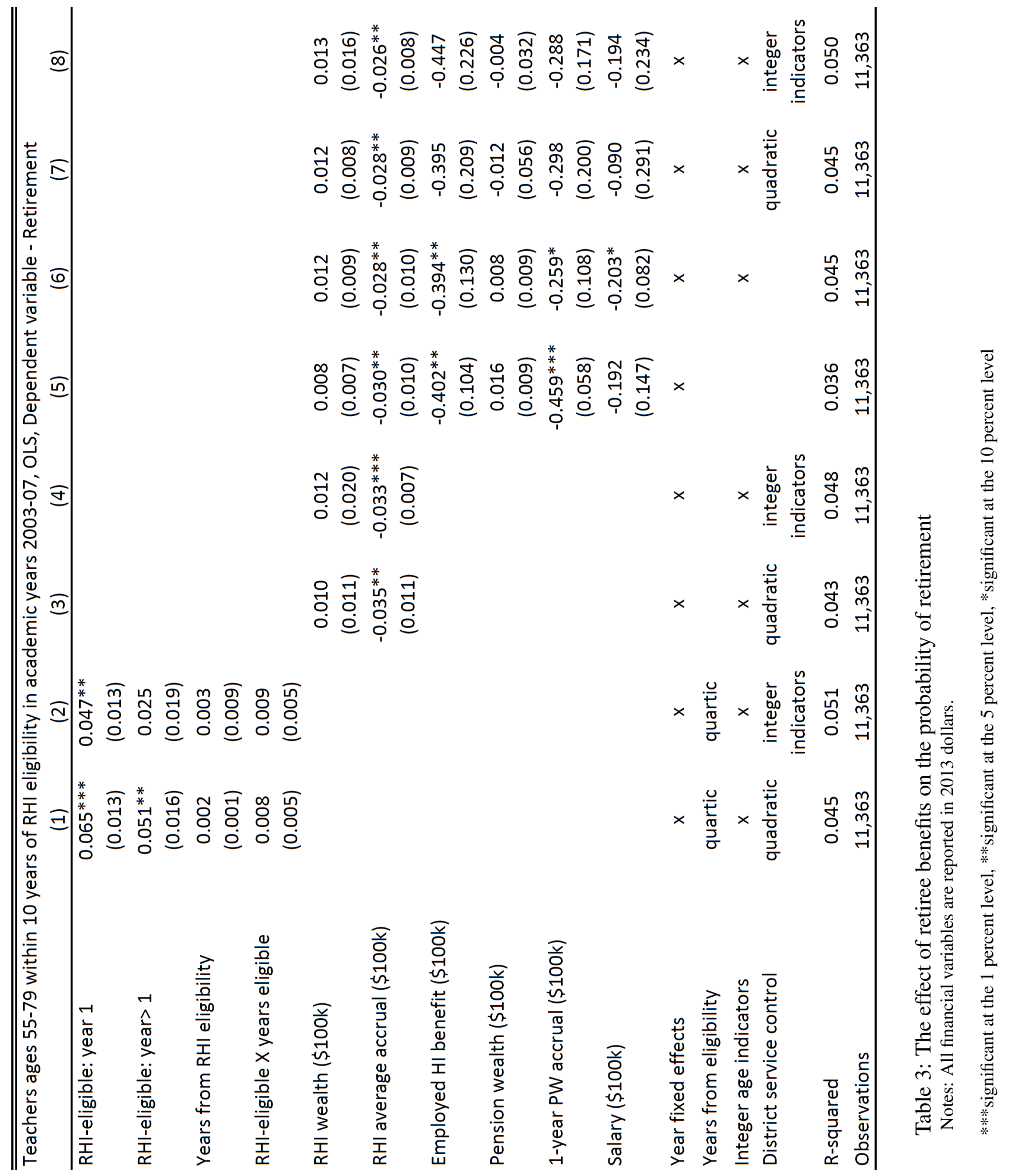




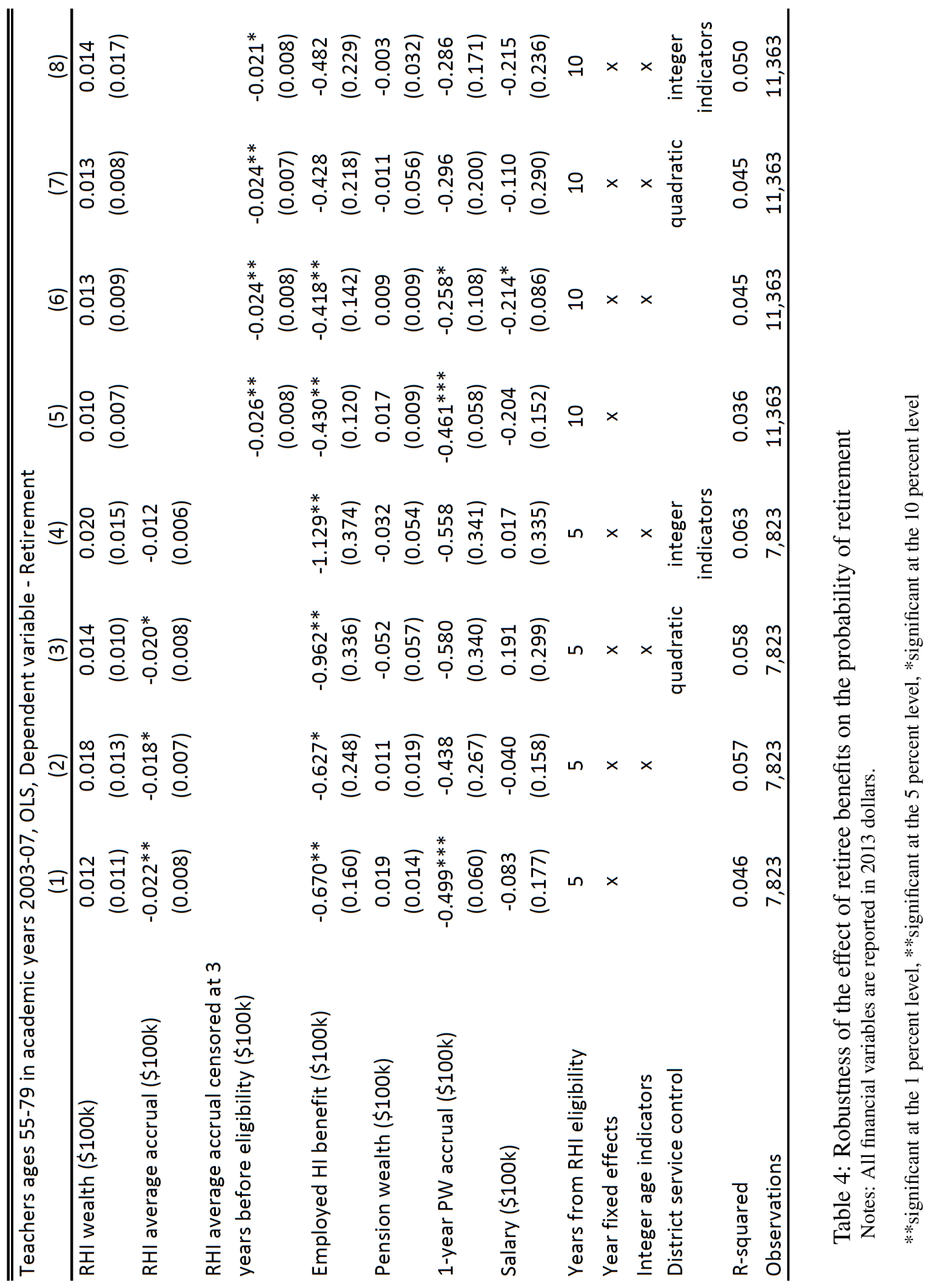




\section{References}

Boyle, Melissa A. and Joanna N. Lahey. 2010. "Health Insurance and the Labor Supply Decisions of Older Workers: Evidence from a U.S. Department of Veterans Affairs Expansion." Journal of Public Economics, 94(7-8): 467-478.

Brown, Kristine M. and Ron A. Laschever. 2012. "When They're Sixty-Four: Peer Effects and the Timing of Retirement.” American Economic Journal: Applied Economics, 4(3): 90-115.

Brown, Kristine M. 2013. "The Link between Pensions and Retirement Timing: Lessons from California Teachers.” Journal of Public Economics, 98: 1-14.

California Department of Education, School Fiscal Services Division. 2012. Selected Certificated Salaries and Related Statistics. Sacramento, CA: California Department of Education.

California State Teachers' Retirement System. 2006. 2006 Health Benefits Survey of Employers. Sacramento, CA: California State Teachers' Retirement System.

California State Teachers' Retirement System. 2012. California State Teachers' Retirement System: Report of Independent Auditors, Basic Financial Statements, Required Supplementary Information, and Other Supplemental Information for the Fiscal Year Ended June 30, 2012. Sacramento, CA: California State Teachers' Retirement System.

Gruber, Jonathan, and Brigitte C. Madrian. 1995. "Health-Insurance Availability and the Retirement Decision." American Economic Review, 85(4): 938-948.

Gruber, Jonathan, and Brigitte C. Madrian. 2004. "Health Insurance, Labor Supply and Job Mobility: A Critical Review of the Literature." in Health Policy and the Uninsured, ed. Catherine McLaughlin. Washington D.C. Urban Institute Press.

Gustman, Alan L., and Thomas L. Steinmeier. 1994. "Employer Provided Health Insurance and Retirement Behavior." Industrial and Labor Relations Review, 48(1): 124-140.

Kleven, Henrik Jacobsen and Mazhar Waseem. 2012. "Behavioral Responses to Notches: Evidence from Pakistani Tax Records.” Quarterly Journal of Economics, 128: 669-723.

Monk, Courtney and Alicia H. Munnell. 2009. "The Implications of Declining Retiree Health Insurance." Working Paper 2009-15. Chestnut Hill, MA: Center for Retirement Research at Boston College.

Saez, Emmanuel. 2010. “Do Taxpayers Bunch at Kink Points?"American Economic Journal: Economic Policy, 2(3): 180-212. 


\section{A Calculation of benefit variables}

Pension wealth for an individual retiring in year $t$ is based on the service years, age, and salary of the teacher in year $t$ and is calculated according to the formula

$$
P W_{t}=\sum_{a=t}^{T} \pi_{a \mid t}\left(\frac{1}{1+r}\right)^{a-t} B_{a}\left(k_{t}, S_{t}, w_{S, t}^{f}\right)
$$

where $\pi_{a \mid t}$ is the probability of living to each future year $a$ given having lived to year $t$, and was computed from the CDC life tables by age and sex, ${ }^{6} T$ is the maximum possible age that can be attained and is assumed to be $100, r$ is the real interest rate and is assumed to be 0.03 . The annual retirement income $B$ is a function of $k_{t}$, the pension benefit factor, which depends on age and ranges from 1.4-2.4 percent, years of service $S_{t}$ and final salary $w_{S, t}^{f}$. Pension wealth accrual is then calculated as $P W_{t+1}-P W_{t}$. Pension benefits also increase by 2 percent of the initial benefit in each retirement year and this is incorporated into the calculation. Salary is assumed to grow by 0.02 per year, but this is only relevant for calculating the future accruals.

Retiree health insurance wealth is calculated the same way as pension wealth, but the sum is over the employer contribution to retiree health insurance premiums. Retiree health insurance average accrual is equal to RHI wealth divided by years to eligibility for those that are not yet eligible and is equal to a loss of one year of premium contributions for those that are already eligible. Note this accrual measure is only used in the probability estimation.

\footnotetext{
${ }^{6}$ United States Life Tables, 2000. National Vital Statistics Report Volume 51, No. 3.
} 


\section{RECENT WORKING PAPERS FROM THE CENTER FOR RETIREMENT RESEARCH AT BOSTON COLLEGE}

The Effect of Increasing Earnings Dispersion on Social Security Payroll Tax Receipts Richard Kopcke, Zhenyu Li, and Anthony Webb, May 2014

What Impact Does Social Security Have on the Use of Public Assistance Programs Among the Elderly?

Norma B. Coe and April Yanyuan Wu, May 2014

Differential Mortality and Retirement Benefits in the Health and Retirement Study Barry P. Bosworth and Kathleen Burke, April 2014

Adding Employer Contributions to Health Insurance To Social Security's Earnings and Tax Base

Karen E. Smith and Eric Toder, April 2014

Lower-Income Individuals Without Pensions: Who Misses Out and Why? April Yanyuan Wu and Matthew S. Rutledge, March 2014

How Do Subjective Longevity Expectations Influence Retirement Plans?

Mashfiqur R. Khan, Matthew S. Rutledge, and April Yanyuan Wu, January 2014

Impact of the Great Recession on Retirement Trends in Industrialized Countries Gary Burtless and Barry P. Bosworth, December 2013

Does Household Debt Influence the Labor Supply and Benefit Claiming Decisions of Older Americans?

Barbara A. Butrica and Nadia S. Karamcheva, December 2013

Point of No Return: How Do Financial Resources Affect the Timing of Retirement After a Job Separation?

Matthew S. Rutledge, December 2013

The Medicaid Buy-In and Social Security Disability Insurance (DI) Beneficiaries: Lessons for the 2014 Medicaid Expansion and Proposals to Reform DI

Melissa McInerney, December 2013

Validating Longitudinal Earnings in Dynamic Microsimulation Models: The Role of Outliers

Melissa M. Favreault and Owen Haaga, September 2013

All working papers are available on the Center for Retirement Research website (http://crr.bc.edu) and can be requested by e-mail (crr@bc.edu) or phone (617-552-1762). 